\title{
ALGORITMA BRUTE FORCE PADA APLIKASI KRITIK DAN SARAN MAHASISWA BERBASIS DIGITAL
}

\section{BRUTE FORCE ALGORITHM IN DIGITAL-BASED STUDENT CRITICISM AND SUGGESTION APPLICATIONS}

\author{
Riyan Wahyu Nur Hidayah ${ }^{1}$, Fauziah ${ }^{2}$, Albaar Rubhasy ${ }^{3}$ \\ Program Studi Teknik Informatika, Fakultas Teknologi Komunikasi dan Informatika, \\ Universitas Nasional ${ }^{1,2,3}$ \\ riyanwahyunurhidayah@gmail.com
}

\begin{abstract}
The Criticism and Suggestion application is an android-based application intended to provide input and criticism to related agencies, in planning to build this application an algorithm method is needed to match strings. This research was made to make it easier for students to express their opinions. The method used is the brute force algorithm method, this method is used to search for terms in the application made, the brute force algorithm is an algorithm that has a straight nature. The brute force algorithm is a very complicated algorithm, the reason is that with this method to solve problems using a straight forward technique, it takes several inputs and valid considerations, so that you often get problem solving decisions that directly refer to the brute force algorithm or lead to the desired results. . The results of the unit area analysis are to make it easier for users or users to generate criticism and input for their fields and therefore the results of the brute force algorithm program will display the results of thoughts, criticisms and inputs for that field.
\end{abstract}

Keywords: The Critique and Suggestion Application, Brute Force Algorithm, Android.

\begin{abstract}
ABSTRAK
Aplikasi Kritik dan Saran yaitu aplikasi berbasis android yang dimaksudkan untuk memberikan masukan dan kritik kepada instansi terkait, dalam merencanakan membangun aplikasi ini diperlukan metode algoritma untuk mencocokan string. penelitian ini dibuat untuk mempermudah mahasiswa dalam penyampaian pendapat. Metode yang digunakkan adalah metode algoritma brute force, metode ini digunakkan untuk mencari istilah pada aplikasi yang dibuat, algoritma brute force yaitu algoritma yang memiliki sifat lurus. Algoritma brute force adalah algoritma yang sangat rumit, alasannya dengan metode ini untuk menyelesaikan masalah dengan menggunakan teknik straight forwad, dibutuhkan beberapa masukan dan juga pertimbangan secara valid, sehingga sering mendapatkan keputusan pemecahan masalah yang langsung mengacu pada algoritma brute force atau mengarah pada hasil yang diinginkan. Hasil analisis unit area untuk memudahkan user atau pengguna dalam menghasilkan kritik dan masukan untuk bidangnya dan oleh karena itu hasil program algoritma brute force akan menampilkan hasil pemikiran, kritik dan masukan untuk bidang tersebut.
\end{abstract}

Kata Kunci: Aplikasi Kritik dan Saran, Algoritma Brute Force, Android.

\section{PENDAHULUAN}

Tentunya setiap universitas menawarkan fasilitas dan pelayanan terbaik kepada setiap mahasiswanya. Namun, jelas bahwa layanan universitas tidak akan pernah sempurna. Cepat atau lambat, setiap orang yang terlibat di dunia akademis akan menghadapi ketidakpuasan terhadap layanan universitas. Untuk dapat meningkatkan dan mengembangkan pelayanan Universitas, segala keluhan dari warga Universitas harus dijadikan sebagai dokumen evaluasi dan ditindak lanjuti(AL-Musawi, 2012).

Kritik dan saran dari mahasiswa merupakan hal penting bagi setiap institusi atau universitas. karena adanya pengeluaran pendapat atau aspirasi, pihak kampus terutama kepada pihak 
kejuruan dapat mempermudah memperbaiki kekurangan serta memperbaiki kualitasnya(Vianita, et al., 2017).

Selama ini banyak sekali mahasiswa/i yang ingin mengeluarkan suara aspirasi kritik dan saran dengan cara datang lansung kepada kepala program studi, sehingga membuat tidak semua mahasiswa berani memberikan aspirasinya. padahal informasi kritik dan saran dari mahasiswa sangat penting dan jika ditindak lanjuti mampu memperbaiki kekurangan untuk meningkatkan kualitas program studi tersebut. jika suara aspirasi yang keluar dari suara mahasiswa/i ditampung terlebih dahulu perlu adanya system yang sesuai untuk menampung semua aspirasi yang diberikan(Febriyanti \& Mukarromah, 2020).

\section{METODE}

Algoritma yang digunakan dalam penelitian konfigurasi aplikasi Kritik dan Saran Berbasis android Dengan Menggunakan metode Algoritma Brute Force. Algoritma Brute Force adalah algoritma dengan kinerja yang sangat rumit, karena untuk menyelesaikan masalah dengan teknik lurus, banyak masukan serta pertimbangan yang dibutuhkan(Jatim, 2020).

\section{Arsitektur Sistem}

Aplikasi kritik dan saran memiliki user yang dibedakan menjadi 2 oleh developer yaitu administrator dan mahasiswa. Sistem aplikasi kritik dan saran sendiri berkerja secara otomatis untuk menampung kritik dan saran dari mahasiwa tanpa mahasiswa datang kekampus. Data dari kritik dan saran mahasiwa disimpan dan akan tampil di database firebase, dengan demikian dapat mempermudah pengelolaan kritik dan saran dari mahasiwa(Vaithyasubramanian, et. al., 2014).

\section{Algoritma Brute Force}

Algoritma brute force adalah algoritma yang sangat rumit, alasannya dengan metode ini untuk menyelesaikan masalah dengan menggunakan teknik straight forwad, dibutuhkan beberapa masukan dan juga pertimbangan secara valid, sehingga sering mendapatkan keputusan pemecahan masalah yang langsung mengacu pada algoritma brute force atau mengarah pada hasil yang diinginkan(Santoso, et.al., 2016).

\section{Cara Kerja}

Berikut ini cara sistematis algoritma brute force saat melakukan pencocokan string(Bošnjak, et al., 2018, Van Heerden \& Vorster, 2009) :

1. Teks dengan pattern yang dibandingkan tidak memiliki kesamaan

2. Algoritma brute force akan menyesuaikan teks dengan pattern dengan bergerak 1 kolom dari kiri ke kanan sampai dapat persamaan dari teks dengan pattern, sampai salah satu kondisi yang dapat terpenuhi:

a. Karakter dalam contoh dan konten yang dipikirkan tidak berkoordinasi (tidak ada kesamaan ).

b. Setiap karakter yang terdapat dalam contoh memiliki persamaan, setelah itu perhitungan secara alami akan menyimpan informasi sesuai posisi yang telah ditemukan.

3. Karakter dalam pattern dan teks pada saat itu secara otomatis bergerak dari kiri ke kanan 1 kali dan mengulangi tahap 2 hingga contoh berada baris terakhir(Rismayani, et al., 2021)

Contoh :

Teks ( X ) : NAMA

Pattern ( Y ) : SYNCHNAMA 
Langkah ke - 1

\begin{tabular}{|l|l|l|l|l|l|l|l|l|l|}
\hline X & N & A & M & A & & & & & \\
\hline Y & S & Y & N & C & H & N & A & M & A \\
\hline
\end{tabular}

Pada langkah yang pertama karakter pada texs $\mathrm{X}$ disimpulkan bahwa tidak ada kecocokan pada pattern $\mathrm{Y}$ dengan demikian teks $\mathrm{X}$ secara otomatis bergeser dari kanan ke kiri sebanyak 1 kali.

Langkah ke - 2

\begin{tabular}{|l|l|l|l|l|l|l|l|l|l|}
\hline $\mathrm{X}$ & & $\mathrm{N}$ & $\mathrm{A}$ & $\mathrm{M}$ & $\mathrm{A}$ & & & & \\
\hline $\mathrm{Y}$ & $\mathrm{S}$ & $\mathrm{Y}$ & $\mathrm{N}$ & $\mathrm{C}$ & $\mathrm{H}$ & $\mathrm{N}$ & A & M & A \\
\hline
\end{tabular}

Pada langkah yang kedua, karakter pada texs X di simpulkan bahwa masih belum ada kesamaan dengan Contoh yang telah ditentukan, maka isi $\mathrm{X}$ dipindahkan ke kanan sekali lagi.

Langkah ke - 3

\begin{tabular}{|l|l|l|l|l|l|l|l|l|l|}
\hline $\mathrm{X}$ & & & $\mathrm{N}$ & $\mathrm{A}$ & $\mathrm{M}$ & $\mathrm{A}$ & & & \\
\hline $\mathrm{Y}$ & $\mathrm{S}$ & $\mathrm{Y}$ & $\mathrm{N}$ & $\mathrm{C}$ & $\mathrm{H}$ & $\mathrm{N}$ & $\mathrm{A}$ & $\mathrm{M}$ & $\mathrm{A}$ \\
\hline
\end{tabular}

Pada langkah yang ketiga karakter pada texs $\mathrm{X}$ masih belum adanya kecocokan dengan Contoh yang telah ditentukan, maka isi $\mathrm{X}$ dipindahkan ke kanan sekali lagi.

Langkah ke -4

\begin{tabular}{|l|l|l|l|l|l|l|l|l|l|}
\hline X & & & & N & A & M & A & & \\
\hline Y & S & Y & N & C & H & N & A & M & A \\
\hline
\end{tabular}

Pada langkah yang keempat karakter pada texs $\mathrm{X}$ masih tidak sama dengan contoh yang telah diselesaikan, maka teks X dipindahkan ke kanan sekali lagi.

Langkah ke-5

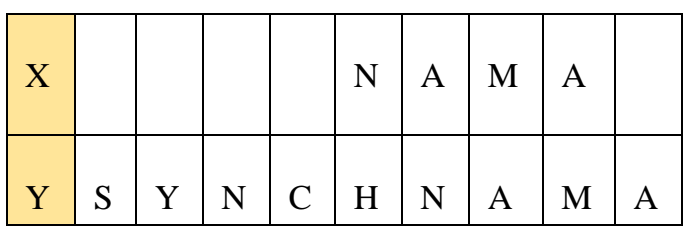

Pada langkah yang kelima karakter pada texs $\mathrm{X}$ masih tidak sama dengan contoh yang telah diselesaikan, maka isi $\mathrm{X}$ dipindahkan ke kanan sekali lagi.

Langkah ke- 6

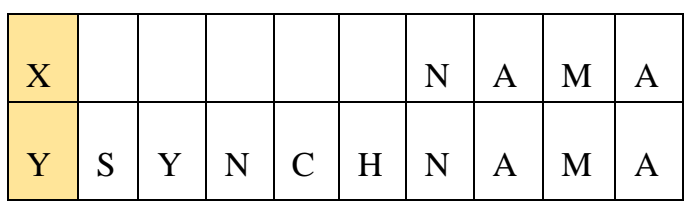

Pada langkah yang ke enam, Langkah terakhir ditemukan kecocokan texs $\mathrm{X}$ dengan pattern Y.dalam contoh kasus diatas merupakan bentuk berjalannya algoritma bruteforce. algoritma bruteforce akan berkerja secara otomatis untuk mencocokan string dengan pattern, jika string tidak ada kecocokan maka string akan menyesuaikan dengan pattern dengan cara menggeser string dari kiri kekanan menyesuaikan pattern hingga diketemukannya kecocokan.

Penelitian ini dilakukan untuk mempermudaah mahasiswa dalam penyampaian kritik dan saran untuk perkembangan serta kemajuan kampus meskipun mahasiswa dirumah.

Analisis Kebutuhan Sistem

Untuk menghasilkan penelitian ini peneliti perlu adanya dukungan dari perangkat keras maupun perangkat lunak yang mendukung untuk merancang aplikasi kritik dan saran mahasiswa berbasis digital, diantaranya: 
Hardware

Spesifikasi Komputer yang digunakkan peneliti dalam merancang aplikasi sebagai berikut:

1) Processor Intel i3 $350 \mathrm{GHz}$.

2) Random Acces Memory 8 GB

3) Harddisk Drive $500 \mathrm{MB}$

4) AMD Radeon HD 6570

Software

Perangkat lunak yang digunakkan dalam merancang aplikasi adalah sebagai berikut(Putra, et. al., 2013):

1) Android Studio

2) Web browser (untuk membuka database firebase)

\section{HASIL DAN PEMBAHASAN}

Pembuatan aplikasi kritik dan saran mahasiswa berbasis digital terdapat penyimpanan data yang dapat menyimpan data saat mahasiswa memberikan kritik serta saran. Oleh sebab itu akan dibuat gambar flowchart gambar yang menunjukkan alur fitur, kritik dan saran yang mengimplementasikan algoritma brute force.

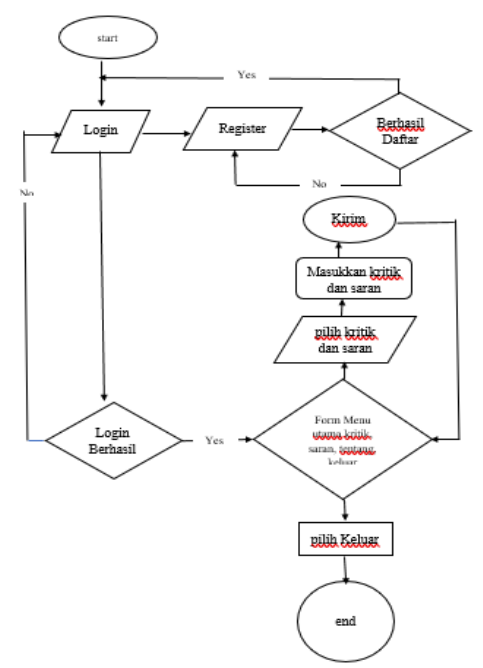

Gambar 1. Alur Aplikasi Kritik Dan Saran

Pada gambar 1. Merupakan alur aplikasi kritik dan saran yang dapat disimpulkan bahwa dalam memberikan kritik dan saran mahasiswa harus memasukkan kritik dan sarannya terlebih dahaulu. Setelah mahasiswa memberikan kritik dan sarannya maka system akan secara otomatis mencari dan mencocokan string dengan pattern dengan menggunakan metode algoritma brute force. jika ditemukan kecocokan maka kritik dan saran dari mahasiswa akan otomatis tersimpan didatabase.

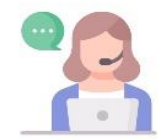

Selamat Datang

Aplikasi Kritik dan Saran merupakan aplikasi yang memberikan masukkan untuk perkembangan kampus kedepannya

Gambar 2. Splash Screen

Pada gambar 2. Merupakan tampilan splash screen saat pertama kali membuka aplikasi. 


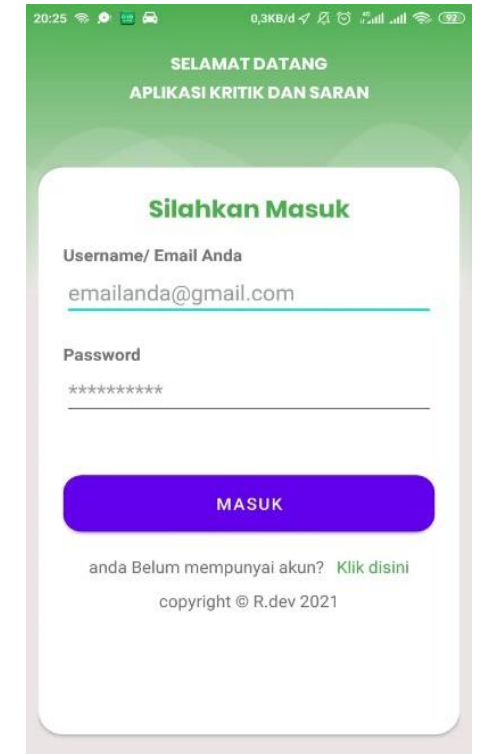

Gambar 3. Tampilan Form Login

Gambar 3. Merupakan tampilan halaman untuk user login secara realtime database, form berisi kolom email dan password untuk masuk kedalam aplikasi.

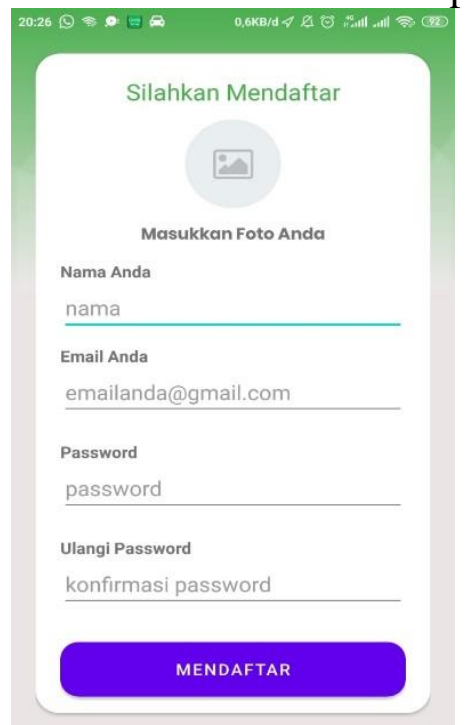

\section{Gambar 4. Tampilan Menu Form Registrasi}

Gambar 4. Merupakan tampilan halaman untuk user registrasi dengan realtime database yang berisi nama, kolom email dan password untuk masuk kedalam aplikasi.

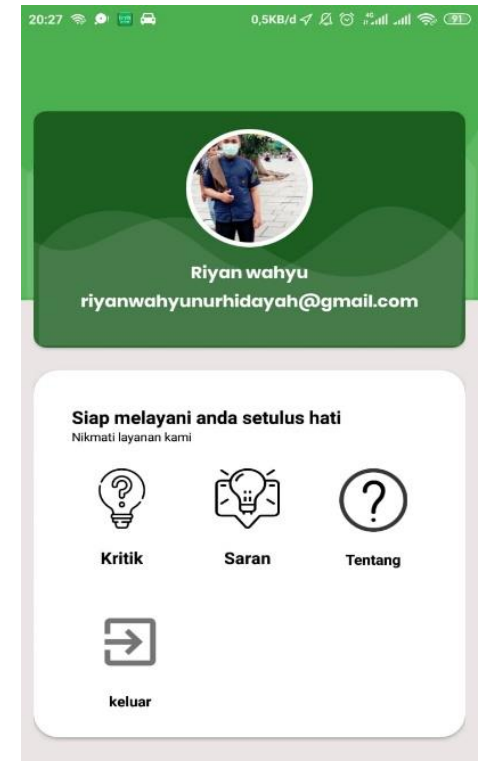

Gambar 5. Halaman Dasboard

Gambar 5. Merupakan desain halaman dashboard yang memiliki beberapa menu pilihan diantaranya kritik, saran, tentang, dan keluar.

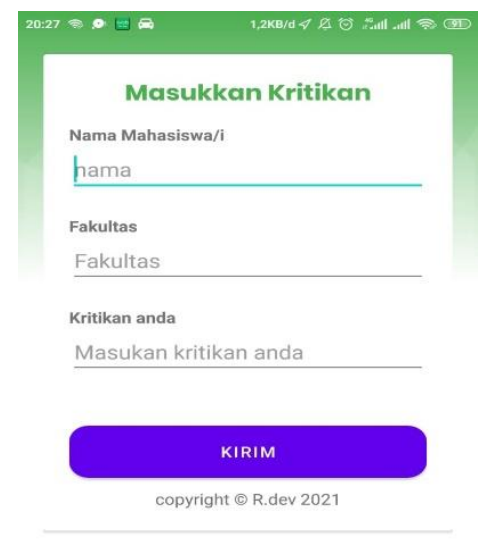

\section{Gambar 6. Halaman Kritikan}

Gambar 6. Merupakan tampilan halaman kritikan yang bisa mahasiswa/i manfaatkan untuk penyampaian kritikan bagi kampus untuk perkembangan yang lebih baik kedepannya. Pada halaman ini terdiri dari kolom pengisian nama, 
kolom pengisian fakultas, serta kolom pengisian kritikan

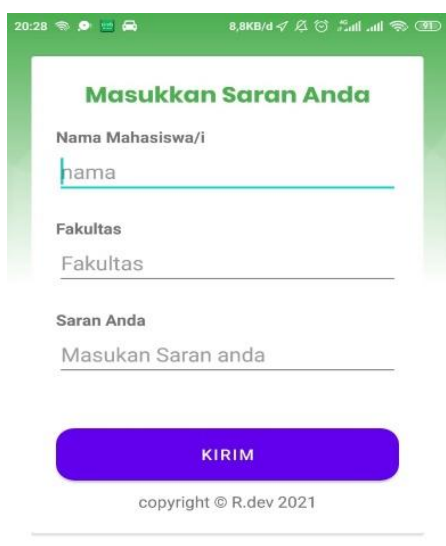

Gambar 7. Halaman Saran

Gambar 7. Merupakan tampilan halaman saran yang bisa mahasiswa/i manfaatkan untuk penyampaian saran bagi kampus untuk perkembangan yang lebih baik kedepannya. Pada halaman ini terdiri dari kolom pengisian nama, kolom pengisian fakultas, serta kolom pengisian Saran

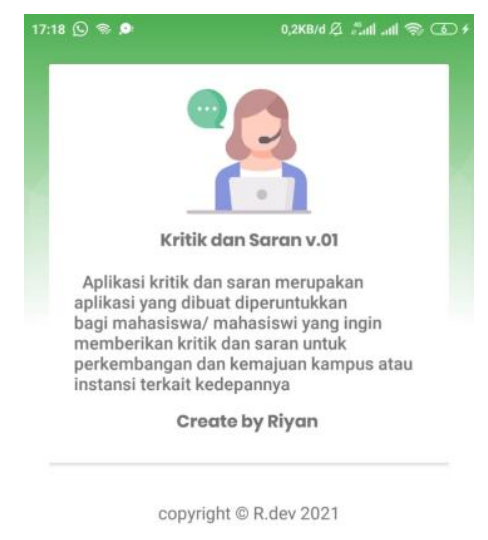

Gambar 8. Halaman Tentang Aplikasi

Gambar 8. Merupakan halaman yang menjelaskan terkait aplikasi

\section{SIMPULAN}

Aplikasi kritik dan saran berbasis android menggunakan algoritma brute force merupakan aplikasi yang di maksudkan dirancang khusus untuk memudahkan mahasiswa-mahasiswi atau pengguna dalam memberikan kritik dan masukan untuk bidangnya. Oleh karena itu hasil program algoritma brute force akan menampilkan hasil pemikiran, kritik dan masukan untuk bidang tersebut agar kritik dan Saranya tertampung dengan baik dan memudahkan fakultas dalam mengelola kritik dan saran dari mahasiswa.

\section{DAFTAR PUSTAKA}

AL-Musawi, B. Q. M. (2012). Preventing brute force attack through the analyzing log. Iraqi Journal of Science, 53(3), 663667.

Bošnjak, L., Sreš, J., \& Brumen, B. (2018, May). Brute-force and dictionary attack on hashed realworld passwords. In 2018 41st International Convention on Information and Communication Technology, Electronics and Microelectronics (MIPRO) (pp. 1161-1166). IEEE.

Febriyanti, D. E. F. E., \& Mukarromah, N. (2020). PERANCANGAN SISTEM Informasi Aplikasi Petir (Pengaduan, Kritik Dan Saran) Mahasiswa Berbasis Digital. Journal of Industrial Engineering and Technology, 1(1), 36-46.

Jatim, A. P. (2020). Sistem Informasi Pengaduan Tenaga Kerja Di Dinas Penanaman Modal Pelayanan Terpadu Satu Pintu Dan Tenaga Kerja Kabupaten Kuantan Singingi. Jurnal Perencanaan, Sains Dan 
Teknologi (JUPERSATEK), 3(2), 291-304.

Putra, P. M., Sunarya, I. M. G., \& Darmawiguna, I. G. M. (2013). Pengembangan Media Kritik dan Saran Universitas Pendidikan Ganesha Berbasis Android Mobile. KARMAPATI (Kumpulan Artikel Mahasiswa Pendidikan Teknik Informatika), 2(5), 556562.

Rismayani, R., Layuk, N. S., Wahyuni, S., Wali, H., \& Marselina, N. K. (2021). Pencarian Kata Pada Aplikasi Kamus Istilah Komputer dan Informatika Menggunakan Algoritma Brute Force Berbasis Android. Komputika: Jurnal Sistem Komputer, 10(1), 43-52.

Santoso, B. W., Sundawa, F., \& Azhari, M. (2016). Implementasi Algoritma Brute Force Sebagai Mesin Pencari (Search Engine) Berbasis Web Pada Database. Jurnal Sisfotek Global, 6(1), 2088-1762.

Vaithyasubramanian, S., Christy, A., \& Saravanan, D. (2014). An analysis of Markov password against brute force attack for effective web applications. Applied Mathematical Sciences, 8(117120), 5823-5830. https://doi.org/10.12988/ams.201 4.47579

Van Heerden, R. P., \& Vorster, J. S. (2009). Statistical analysis of large passwords lists, used to optimize brute force attacks.

Vianita, R., Sukamto, S., \& Perwitasari, A. (2017). Aplikasi Kotak Saran Digital Rumah Sakit Berbasis Android. Sistem Dan Teknologi Informasi, 5(4), 177. 